\title{
Vas Deferens Anastomotic Leak, CTCAE
}

National Cancer Institute

\section{Source}

National Cancer Institute. Vas Deferens Anastomotic Leak, CTCAE. NCI Thesaurus. Code C143928.

A finding of leakage due to breakdown of a vas deferens anastomosis (surgical connection of two separate anatomic structures). 